\title{
An Instrument for Assessing E-Commerce Web Object Designs against Guidelines for Older Adults
}

\author{
Rozianawaty Osman \\ University of Reading, UK \\ Universiti Teknologi MARA, Malaysia \\ r.osman@pgr.reading.ac.uk
}

\author{
Faustina Hwang \\ University of Reading, UK \\ f.hwang@reading.ac.uk
}

\begin{abstract}
Older adults are often reported to have difficulties with navigating websites. In a previous study, we found that one of the difficulties encountered by older adults while navigating an online grocery shopping site was an inability to recognise the 'add to cart' button. We propose to conduct a study to assess the existing button designs applied in e-commerce websites against principles and guidelines for designing for older adults. In this paper we focus on the development of the instrument to be used in the assessment. This instrument includes assessment criteria relating to button visibility, readability, understandability and navigability, which are drawn from existing principles and guidelines on web design for older adults.
\end{abstract}

Ageing, online shopping, web navigation, font, contrast, button design, add to cart.

\section{INTRODUCTION}

The older population is increasing, and the number of people using the Internet within this population are also increasing. Online shopping is among the top ten computer activities among older adults when they are online (Vroman et al. 2015). Online shopping has been seen as an attractive alternative when physical disabilities hinder older adults from doing traditional in-store shopping. These include difficulties in driving, lifting heavy loads (Morganosky \& Cude 2000) and being able to move and walk at a desirable pace (Meneely et al. 2009).

For e-commerce websites, successful web navigation has potential monetary value, while frustration due to navigation difficulties (e.g. disorientation) could lead to the abandonment of the site and hence lost revenue.

Although websites employ a variety of web navigation features, such as core navigation (i.e. main menu), links, breadcrumbs and others, to provide access to information or indicate location, older adults still often experience navigation difficulties (Murata \& Moriwaka 2008; Sjölinder \& Höök 2000). Consistent with these previous reports, we also found, in an earlier exploratory study, that older users experienced navigation difficulties in an online grocery shopping site. Difficulty in identifying and selecting 'add to cart' buttons was found to be one of the difficulties. Yet, the 'add to cart' button plays an important role in ecommerce websites as it is a crucial element in enabling actual sales to start.

A combination of ever-advancing technology, an ageing population, and older adults' experience of age-related decline in abilities suggests that a lag in technology adoption among the older population may persist for some time. Although this gap in older adults' abilities to use the latest technologies may never be completely eliminated, minimizing this gap is possible by providing better design guidelines, and tools that cater for older adults' needs and capabilities (Charness \& Boot 2009).

For web design in particular, more appropriate design could improve ease of use and help older users to interact with websites (Lin 2004). A better understanding of the designs practised on existing websites can provide a good starting point for improvements to take place. This paper describes the design of an instrument for systematically assessing current practices for 'add to cart' button designs, with a view to highlighting areas that need improvement in respect of designing for older adults. The instrument draws on available principles, guidelines and recommendations for general web design for older people, but focuses particularly on button design for its relevance to 'add to cart' button design in e-commerce sites. 


\section{DESIGNING THE EVALUATION INSTRUMENT}

The design of the evaluation instrument involved three stages: determining the main areas to include in the evaluation, identifying relevant design guidelines relating to those areas, and refining the evaluation instrument.

\subsection{Determining the main areas for evaluation}

Becker (2004) notes that vision, cognition, and motor skills play an important role in helping older users to use a website. However, these abilities deteriorate with age. Human visual ability is said to start declining between 30 to 40 years of age, and significantly worsens around the age of 65 . A person may experience a decline in their ability to adapt to darkness, illumination sensitivity, visual acuity, and also experience hypersensitivity to glare as well as a reduction in the size of their visual field (Fisk et al. 2004). To accommodate changes in visual ability, aspects to be considered when designing systems relate primarily to visibility and readability. For example, Fisk et al. (2004) suggest that text should have appropriate font size, style, spacing, and contrast ratio.

Cognitive ability also decreases with age (Biswas \& Langdon 2013); and short-term memory problems are clearly seen with ageing (Arch 2008; Saldaño et al. 2014). As information is processed more slowly, it may cause a reduction in the response time of older adults (Raza \& Sahar 2013), and this is possibly the reason why older adults' navigation time is twice that of younger people (Sjölinder \& Höök 2000). Problems relating to cognitive abilities can also be seen when a technology with a complex interface design, is presented to older adults (Harte et al. 2014). Complex interface designs leading to difficulty or inability to decipher the meaning of the interface is one of the barriers to technology adoption for older adults. Therefore, designs for older users should be easy to interpret and understand.

Ageing may also affect a person's physical ability, for example in terms of their control of movement. Older adults experience declines in the ability to control body position or movement, contributing to being less precise, having slow responses and being more error-prone (Fisk et al. 2004). These affect task performance, and consequently, older adults need more time to perform tasks compared to younger people (Sjölinder et al. 2005; Sjölinder \& Höök 2000). For example, a study by (Raza \& Sahar 2013) that investigated usability and functionality of mobile phone for older adults found that small buttons and small displays caused difficulties in using the technology. Thus, objects should be big enough for older users to click and navigate.

Taking into consideration the deterioration in visual, cognitive and physical abilities that people experience in older age, therefore, visibility, readability, understandability and navigability were identified as the main areas to be included in the evaluation instrument.

\subsection{Identifying relevant design guidelines}

After the main areas to be included in the evaluation instrument were determined, the next step was to identify relevant design guidelines relating to each area. The guidelines were to be drawn from existing sources, and hence a review of relevant sources was conducted.

As mentioned by Kurniawan and Zaphiris (Kurniawan \& Zaphiris 2005), sources of web design guidelines can be derived from two main streams, that is, academia and industry and these formed the basis for the selection of sources. The sources used in this study are (i) relevant principles and guidelines on designing websites for older adults (Arch \& AbouZahra 2010; Hodes \& Lindberg 2002), (ii) academic research discussing design for older users, design of e-commerce websites, and design of web buttons (Zaphiris et al. 2007; Najjar 2011; Burt \& Gibbons 2011; Wells 2003), and (iii) recommendations by practitioners (designers/developers) on the design of 'add to cart' buttons (Bustos 2007; Chaparro 2002; Grath 2013; Messmer 2015; Naidu \& Chaparro 2007).

The Web Accessibility Initiative (WAI) develops guidelines for Web accessibility, and its Web Content Accessibility Guidelines WCAG 2.0 (Caldwell, Ben and Cooper, Michael and Reid, Loretta Guarino and Vanderheiden 2008) are widelyaccepted in web design. WCAG also include guidelines and techniques for designs that work better for older users with accessibility needs due to ageing (Arch \& Abou-Zahra 2010). Guidelines for designing websites targeting older users have also been developed by The National Institute of Aging and National Library of Medicine (NIA/NLM) (Hodes \& Lindberg 2002). These guidelines have been cited in many articles, for example in (Hart et al. 2008) which examined the adherence of 40 websites designed for older adults to the guidelines and found that higher success rates of tasks performed were associated with websites that were most compliant to the 'senior-friendly' guidelines. Furthermore, Zaphiris et al. (2007) have published the SilverWeb Guidelines, which extends their previous work (Kurniawan \& Zaphiris 2005).

(Najjar 2011) offers guidance on designing ecommerce websites, covering the major sections such as registration, catalogue, and checkout. The paper includes a discussion on the design of 'add to cart' buttons.

Academic articles discussing button designs specifically were also included in the review of sources of guidelines. Burt and Gibbons in their article (2011) discussed the effects of donation 
button designs on trust. Through website surveys, several design features including shape, location, the word used on the button, and icons used were reviewed. The results showed that the donation button designs were used to explain the functions and to capture attention, rather than facilitating trust. Only when appropriate information was associated with a button was there an increase in trust. Wells (2003) examined the location of the chat request button for academic chat reference services available in online academic libraries with regards to the usage of services. Based on the data collected through a longitudinal study, it was found that buttons, when placed at appropriate locations, could increase service usage.

Articles from the industry perspective that have discussed 'add to cart' button designs were also examined. An evaluation of 'add to cart' button designs practised on e-commerce websites in 2006 was documented (Bustos 2007), and the same websites were re-evaluated in 2014 (Messmer 2015). Among the aspects evaluated were text, icons, size, shape, and colour used for buttons.

Some of these sources provide overall web design recommendations while others specifically discuss button designs and 'add to cart' button designs. While the general web design recommendations are not specifically about buttons, in many cases, they still apply to button designs. For example, 'use high contrast between text and background' applies equally to buttons as it does overall web design. From the identified sources, recommendations relevant for button designs were extracted and grouped into the main criteria of evaluation defined in 2.1. For example, 'use large buttons' was extracted from NIA/NLM guidelines and grouped into navigability, as large buttons which are easier to click on can ease navigation.

The first version of the evaluation instrument consisted of the derived list of recommendations which were scored on a 'yes/no' basis in terms of whether or not button designs met the recommendations.

\subsection{Refining the evaluation instrument}

The instrument was refined by reducing redundant guideline practices and revising the instrument in a pilot study. To reduce redundancy, any recommendations that carried similar meaning were merged. For instance, one suggestion was to 'include concise text labels with icons' (Hodes \& Lindberg 2002). The two components of this suggestion, (i) use concise text, and (ii) use text and icons together, were merged with two suggestions from other sources that carried similar meaning 'provide descriptive labels' (Arch \& Abou-Zahra 2010) and 'combine text with graphic/icon (e.g. shopping cart)' (Chaparro 2002; Naidu \& Chaparro 2007; Burt \& Gibbons 2011).
The evaluation instrument was piloted on five websites. The results from the pilot assessment highlighted further revisions to be made to the instrument. One of the revisions involved the visibility criterion which was 'use a different colour from the surrounding (background)' (Hodes \& Lindberg 2002). This was revised such that the evaluation instrument would specifically take note of the button colour and the surrounding colour. The guideline that suggested 'any link should be visually distinct' (Arch \& Abou-Zahra 2010; Bustos 2007) was further itemised as two criteria which relate to buttons being 'visually distinct': 'use a different shape from other elements' and 'use a different colour from other elements', as both shape and colour can influence visibility as these attributes can help with attention (Wolfe \& Horowitz 2004). The assessment of the button shape criterion to use a 'rectangle with rounded corner' (Messmer 2015) was also revised, from being a 'yes/no' response to taking note of the shape used and whether or not the corners were rounded (if rectangular).

Regarding button location, the published guidelines only suggest locating the button appropriately (Wells 2003); however, this is wide open to interpretation. The evaluation instrument was revised to include an item for matching the design layout of the evaluated page to one of five design layouts described in (Bryant \& Jones 2012). In the case that there was no suitable layout matching the page being evaluated, a new layout could be added to the design layouts list.

One font guideline was to 'use non-condensed typeface' (Hodes \& Lindberg 2002). Since it was difficult to assess whether fonts were condensed or not, the instrument was revised to note letter spacing.

Instead of providing a 'yes/no' answer to the criterion 'provide visual feedback when an item has been added to the cart' (Chaparro 2002; Naidu \& Chaparro 2007; Najjar 2011), the instrument was revised such that the exact feedback used is noted.

The guideline to "combine text with graphic/icon (e.g. shopping cart)' was revised so that a note was made of the actual graphic/icon used.

As mentioned in (Harte et al. 2014), too many clicks may imply a negative user experience. Thus, the assessment of the click criterion 'use single click or screen taps to access information' (Hodes \& Lindberg 2002) was also modified such that the 'number of clicks to add item to cart from the first page that the product image is viewed' is also recorded. This is significant as it dictates the number of steps users need to take in order to complete the task of adding an item to the cart.

Large buttons were recommended by the published guidelines (Hodes \& Lindberg 2002); however, no exact measurements were provided for a button to be considered large. Thus the assessment 
instrument was revised to include a space for recording the width and height of the button, as this data could be analysed to get an indication of the button sizes which are being used in current websites.

\section{RESULTS}

The evaluation instrument that can be used for the evaluation of button designs in e-commerce websites is as follows:

Table 1: Evaluation instrument and possible assessment results [in brackets]

\begin{tabular}{|c|c|}
\hline Criteria & Guidelines/Practices/Suggestions \\
\hline Visible & Make buttons stand out. \\
\hline Colour & $\begin{array}{l}\text { - Use different colour from the } \\
\text { surrounding. } \\
\circ \quad \text { [Button colour] } \\
\circ \quad \text { [Surrounding colour] } \\
\text { - Dark buttons/icons against a } \\
\text { light background. [yes/no] } \\
\text { - Use bright colour. [yes/no] }\end{array}$ \\
\hline Visual Cues & 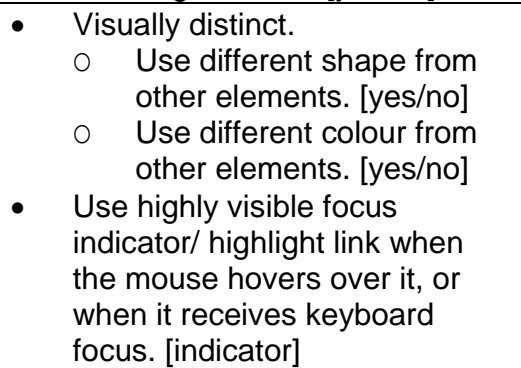 \\
\hline Shape & $\begin{array}{l}\text { - Rectangle with/without rounded } \\
\text { corner. } \\
0 \quad[\text { Shape] } \\
0 \text { Rounded corner (if } \\
\\
\text { rectangle) [yes/no] }\end{array}$ \\
\hline Location & $\begin{array}{ll}\text { - } & \text { Place button appropriately. } \\
0 & \text { [Design layout] }\end{array}$ \\
\hline Readable & - Make the text easier to read. \\
\hline Background & $\begin{array}{l}\text { - Avoid patterned background. } \\
\text { [yes/no] }\end{array}$ \\
\hline Contrast & $\begin{array}{l}\text { - Use high contrast between text } \\
\text { and background. } \\
\circ \text { [Text colour] } \\
\circ \text { [Background colour] }\end{array}$ \\
\hline Case text & $\begin{array}{ll} & \text { Uppercase } \\
- & \text { Mixed case } \\
& \text { [uppercase/lowercase/ mixed] }\end{array}$ \\
\hline Font & $\begin{array}{ll}\text { - } & \text { Avoid using underline for text } \\
\text { that is not link. [yes/no] } \\
\text { - } \quad \text { Use large font size. [font size] } \\
\text { - } \quad \text { Avoid text in raster image. } \\
\text { [yes/no] } \\
\text { - } \quad \text { Avoid chunks of italic text. } \\
\text { [yes/no] } \\
\text { - Use san serif typeface. } \\
\text { - Use non-condensed typeface } \\
\text { - } \quad \text { [Typeface] } \\
\text { Use medium or boldface } \\
\text { typeface. [yes/no] }\end{array}$ \\
\hline
\end{tabular}

\begin{tabular}{|c|c|}
\hline Space & $\begin{array}{l}\text { - Allow enough white space to } \\
\text { ensure an uncluttered look. } \\
\text { [yes/no] }\end{array}$ \\
\hline Understandable & $\begin{array}{l}\text { Able to convey the intended } \\
\text { meaning. }\end{array}$ \\
\hline Consistent & $\begin{array}{l}\text { Use labels, names an d text } \\
\text { alternatives consistently for } \\
\text { content that has same } \\
\text { functionality. [yes/no] }\end{array}$ \\
\hline Feedback & $\begin{array}{l}\text { Provide visual feedback when } \\
\text { an item has been added to the } \\
\text { cart. [feedback] }\end{array}$ \\
\hline Label & $\begin{array}{l}\text { - } \begin{array}{l}\text { Provide descriptive label. [text } \\
\text { on button] }\end{array} \\
\text { - Use either "Add to cart" or "Add } \\
\text { to basket" or "Add to bag". } \\
\text { [yes/no] } \\
\text { - Avoid "Buy' unless it is used to } \\
\text { convey immediate purchase } \\
\text { commitments. [yes/no] } \\
\text { Combine text with graphic/icon } \\
\text { (e.g. shopping cart). [yes/no] } \\
\text { [Graphic/icon used] }\end{array}$ \\
\hline Language & $\begin{array}{l}\text { - Use the clearest and simplest } \\
\text { language appropriate for the } \\
\text { content. [yes/no] } \\
\text { - Use verbs to signal action. } \\
\text { [yes/no] }\end{array}$ \\
\hline Navigable & Easy to activate the button. \\
\hline Click/tap & $\begin{array}{l}\text { - Use single click or screen taps } \\
\text { to access information. [yes/no] } \\
\text { o Number of clicks to add } \\
\text { item to cart from the first } \\
\text { seen product image. } \\
\text { [number of clicks] } \\
\text { - If the button includes a link, } \\
\text { hyperlink the entire button, not } \\
\text { just the text. [yes/no] }\end{array}$ \\
\hline Size & $\begin{array}{ll} & \text { Use large buttons. } \\
\circ & \text { [Width] } \\
\circ & \text { [Height] }\end{array}$ \\
\hline Space & $\begin{array}{l}\text { - Enough space around clickable } \\
\text { targets. [yes/no] }\end{array}$ \\
\hline
\end{tabular}

\section{FUTURE WORK}

This paper presents a new evaluation instrument for assessing 'add to cart' buttons. The instrument includes criteria for four main areas which are visibility, readability, understandability and navigability. A future study will use the evaluation instrument in a survey of the 'add to cart' button designs of existing e-commerce websites. Designs will be analysed for their adherence to the principles and guidelines, thus enabling us to uncover areas that may need improvement for easier navigation for older users. Identifying recurring 'unfriendly' design practices can be a starting point for making e-commerce sites more accessible for older adults. 


\section{REFERENCES}

Arch, A., 2008. Web accessibility for older users: A literature review. Available at: http://www.w3.org/TR/2008/WD-wai-ageliterature-20080514/ [Accessed October 23, 2015].

Arch, A. and Abou-Zahra, S., 2010. Developing websites for older people: How web content accessibility guidelines (WCAG) 2.0 applies. Web Accessibility Initiative. Available at: http://www.w3.org/WAl/olderusers/developing.html [Accessed April 1, 2017].

Becker, S.A., 2004. A study of web usability for older adults seeking online health resources. ACM Transactions on Computer-Human Interaction, 11(4), pp.387-406.

Biswas, P. and Langdon, P.M., 2013. A survey on technology exposure and range of abilities of elderly and disabled users in India. In Universal Access in Human-Computer Interaction. User and Context Diversity. Springer, pp. 23-31.

Burt, C.D. and Gibbons, S., 2011. The effects of donation button design on aid agency transactional trust. International Journal of Nonprofit and Voluntary Sector Marketing, 16, pp.183-194.

Bustos, L., 2007. 107 Add to cart buttons of the top online retailers. Get Elastic. Available at: http://www.getelastic.com/add-to-cart-buttons/ [Accessed April 1, 2017].

Caldwell, B., Cooper, M. and Reid, Loretta Guarino Vanderheiden, G., 2008. Web Content Accessibility Guidelines 2.0. WWW Consortium (W3C). Available at: https://www.w3.org/TR/WCAG20/.

Chaparro, B.S., 2002. Top Ten Mistakes of Shopping Cart Design. Software Usability Research laboratory Whichita State University. Available at: http://usabilitynews.org/top-tenmistakes-of-shopping-cart-design/ [Accessed April 1, 2017].

Charness, N. and Boot, W.R., 2009. Aging and information technology use: Potential and barriers. Current Directions in Psychological Science, 18(253), pp.253-258.

Fisk, A.D. et al., 2004. Designing for older adults: Principles and creative human factors approaches, CRC Press.

Grath, E.M., 2013. Top 9 E-Commerce Usability Guidelines. Usability Geek. Available at: http://usabilitygeek.com/top-9-e-commerceusability-guidelines/ [Accessed April 1, 2017].
Hart, T.A., Chaparro, B.S. and Halcomb, C.G., 2008. Evaluating websites for older adults: Adherence to "senior-friendly" guidelines and end-user performance. Behaviour and Information Technology, 27(3), pp.191-199.

Harte, R. et al., 2014. Human centred design considerations for connected health devices for the older adult. Journal of Personalized Medicine, 4(2), pp.245-281.

Hodes, R.J. and Lindberg, D.A., 2002. Making your web site senior friendly. National Institute on Aging and the National Library of Medicine.

Kurniawan, S. and Zaphiris, P., 2005. Researchderived web design guidelines for older people. Proceedings of the 7th international ACM SIGACCESS conference on Computers and accessibility - Assets '05, pp.129-135.

Lin, D.-Y.M., 2004. A Comparison of Navigation Performances between Older and Young Adults in Hypermedia E-Mall Shopping. In The 8th ERCIM Workshop "User Interfaces For All", Universal access in interactive applications and e-services. Citeseer, pp. 28-29.

Meneely, L., Strugnell, C. and Burns, A., 2009. Elderly consumers and their food store experiences. Journal of Retailing and Consumer Services, 16(6), pp.458-465.

Messmer, P., 2015. Add to Cart Buttons: A 7 Year Analysis. AddShoppers. Available at: https://www.addshoppers.com/blog/add-tocart-buttons-a-7-year-analysis [Accessed April 1, 2017].

Morganosky, M.A. and Cude, B.J., 2000. Consumer response to online grocery shopping. International Journal of Retail \& Distribution Management, 28(1), pp.17-26.

Murata, A. and Moriwaka, M., 2008. Usability of site map in web design - Design of site map that is friendly to older adults-. In Proc. Fourth International Workshop on Computational Intelligence I\& Applications. pp. 121-126.

Naidu, S. and Chaparro, B.S., 2007. Top ten mistakes of shopping cart design revisited: A survey of 500 top e-commerce websites. Software Usability Research laboratory Whichita State University. Available at: http://usabilitynews.org/top-ten-mistakes-ofshopping-cart-design-revisited-a-survey-of500-top-e-commerce-websites/ [Accessed April 1, 2017].

Najjar, L.J., 2017. Designing e-commerce user interfaces. In K.-P. L. Vu \& R. W. Proctor, eds. Handbook of Human Factors in Web Design, Second Edition. CRC Press, pp.587-598. 
Raza, S.T. \& Sahar, F., 2013. An investigation on perspective of usability and functionality of mobile phones for elderly. International Journal of Engineering and Technology, 5(3), pp.398401.

Saldaño, V. et al., 2014. Focusing on older web users: An experience in Patagonia Argentina. International Journal on Advances in Internet Technology. IARIA, 7, pp.172-182.

Sjölinder, M. et al., 2005. Age differences and the acquisition of spatial knowledge in a threedimensional environment: Evaluating the use of an overview map as a navigation aid. International Journal of Human Computer Studies, 63(6), pp.537-564.

Sjölinder, M. and Höök, K., 2000. Age differences in the use of an on-line grocery shop Implications for design. In CHI'OO extended abstracts on Human Factors in Computing
Systems. ACM, pp. 135-136.

Vroman, K.G., Arthanat, S. and Lysack, C., 2015. "Who over 65 is online?" Older adults' dispositions toward information communication technology. Computers in Human Behavior, 43, pp.156-166.

Wells, C.A., 2003. Location, location, location: The importance of placement of the chat request button. Reference \& User Services Quarterly, 43(2), pp.133-137.

Wolfe, J.M. and Horowitz, T.S., 2004. Opinion: What attributes guide the deployment of visual attention and how do they do it? Nature Reviews Neuroscience, 5(6), pp.495-501.

Zaphiris, P., Kurniawan, S. and Ghiawadwala, M., 2007. A systematic approach to the development of research-based web design guidelines for older people. Universal Access in the Information Society, 6(1), pp.59-75. 